\title{
Analysis of the Detection and Influencing Factors of Dyslipidemia in the Elderly in Wuwei区 A Community-based Study
}

\author{
Xiaochun Li \\ Wuiwei municipal Center for Disease Control and Prevention \\ Junshan Yang \\ Wuwei People's Hospital \\ Zhaohua Ji ( $\nabla$ hellojzh@msn.com ) \\ Airforce Military Medical University
}

Research article

Keywords: dyslipidemia, incidence, risk factors

Posted Date: October 1st, 2020

DOI: https://doi.org/10.21203/rs.3.rs-65476/v1

License: (a) (i) This work is licensed under a Creative Commons Attribution 4.0 International License. Read Full License 


\section{Abstract}

Background: This study aimed to investigate the distribution of the incidence of dyslipidemia among the elderly in Wuwei, and explore the related factors affecting dyslipidemia.

Methods: The physical examination data of 43,092 elder people aged 60 and over from 2012 to 2019 in Wuwei city were collected to analyze the incidence of dyslipidemia, and the factors affecting dyslipidemia were evaluated by univariate and multivariate analysis.

Results: A total of 12,338 cases of dyslipidemia were reported in 43,092 patients, and the incidence of dyslipidemia was $28.6 \%$. Among these dyslipidemia patients, the proportion of patients with low high-density lipoprotein cholesterol was the highest, and the proportion of patients with hypertriglyceridemia combined with low high-density lipoprotein cholesterol was the lowest. Univariate analysis showed that age, gender, smoking, alcohol consumption, blood glucose, blood pressure, weight, electrocardiogram, and total bilirubin were the influencing factors of dyslipidemia in the elderly, and the differences were statistically significant $(P<0.05)$. Multivariate logistic regression analysis indicated that female gender, overweight/obesity, abnormal blood glucose, and high alanine aminotransferase were independent risk factors for dyslipidemia in the elderly $(P<$ 0.05).

Conclusions: The age with the highest prevalence of dyslipidemia among the elderly in Wuwei city is 70-80 years old. Elderly women should strengthen the prevention and treatment of dyslipidemia. In order to avoid the occurrence of dyslipidemia, it is necessary to control body weight, blood glucose and improve liver function.

\section{Background}

Blood lipids are a general term for cholesterol, triacylglycerol (TG) and lipids (such as phospholipids) in serum, and the clinically relevant blood lipids are mainly cholesterol and TG. Dyslipidemia refers to abnormal metabolism of lipoproteins in the human body, mainly including elevated total cholesterol (TC), low-density lipoprotein cholesterol (LDL-C) and triacylglycerol (TG) levels, or decreased high-density lipoprotein cholesterol (HDL-C) levels ${ }^{[1]}$. Some research reports have pointed out that the prevalence of

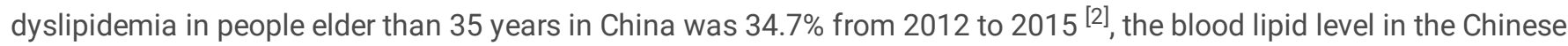
population gradually increased, and the detection rate of dyslipidemia significantly increased ${ }^{[3]}$. Dyslipidemia is one of the important mechanisms leading to atherosclerosis, which in turn leads to the occurrence of cardiovascular and cerebrovascular diseases ${ }^{[4]}$. The incidence of cardiovascular diseases is high among the elderly, and the incidence increases with the aggravation of the aging phenomenon in China. Therefore, the prevention and treatment of dyslipidemia in the elderly have become a clinical concern. At present, there are few surveys or studies on dyslipidemia in the elderly in northwest China. Based on the above reasons, this study retrospectively analyzed the physical examination data of the elderly in Wuwei City, investigated the epidemic status of dyslipidemia in Wuwei City and analyzed its possible risk factors to provide a reference for the current status and prevention of dyslipidemia.

\section{Methods}

\subsection{Study object}

A retrospective analysis of the elderly population underwent routine physical examinations from 2012 to 2019 in Dongguan Street Community Medical Examination Center, Liangzhou District, Wuwei City. A total of 43092 subjects with complete physical examination data were included in this analysis, including 24553 males (57\%) and 18539 females (43\%), aged 64-104 years, with a mean age of $(72.37+5.46)$ years. In this analysis, only the age, gender and physical examination conclusion of the study subjects are extracted for data analysis, and no personal identity information and medical ethics issues of the traceable study subjects are involved. Therefore, informed consent and ethical review of the study subjects are not required.

\subsection{Methods}


In this study, the data of the physical examination report were analyzed based on the criteria or guidelines for biochemical indicators for related diseases of dyslipidemia, and the abnormal electrocardiograph (ECG) results in the physical examination report were directly used for analysis. The conclusion of the subjects' disease and the judgment results of the indicators were summarized as binary variables (i.e., normal/abnormal or normal/high). Besides, the drinking and smoking status of subjects were recorded and analyzed.

\subsection{Diagnostic criteria}

According to the "2016 Chinese guideline for the management of dyslipidemia in adults", dyslipidemia was defined as TC $\geq 5.2$ $\mathrm{mmol} / \mathrm{L}, \mathrm{TG} \geq 1.7 \mathrm{mmol} / \mathrm{L}, \mathrm{LDL}-\mathrm{C} \geq 3.4 \mathrm{mmol} / \mathrm{L}$, and HDL-C $<1.0 \mathrm{mmol} / \mathrm{L}$. Abnormalities in any one or more of the above indicators can be judged as dyslipidemia. Dyslipidemias can be generally divided into hypercholesterolemia, hypertriglycerdemia, mixed hyperlipidemia, and Low HDL-C.

Criteria for overweight and obesity have given in "The Guidelines for Prevention and Control of Overweight and Obesity in Chinese Adults": Body mass index (BMI) is calculated as weight in kilograms divided by the square of height in meters. BMI < 18.5 is considered underweight, $18.5 \mathrm{~kg} / \mathrm{m}^{2} \leq \mathrm{BMI}<24.0 \mathrm{~kg} / \mathrm{m}^{2}$ is considered normal, $24.0 \mathrm{~kg} / \mathrm{m}^{2} \leq \mathrm{BMI}<28.0 \mathrm{~kg} / \mathrm{m}^{2}$ is considered overweight, and $\mathrm{BMI} \geq 28.0 \mathrm{~kg} / \mathrm{m}^{2}$ is obesity.

Criteria for hypertension: systolic blood pressure (SBP) $\geq 140 \mathrm{~mm} \mathrm{Hg}$ and diastolic blood pressure (DBP) $\geq 90 \mathrm{~mm} \mathrm{Hg}^{[5]}$. Criteria for hyperglycemia: according to the diagnostic criteria adopted by Chinese Diabetes Association in October 1999: fasting blood glucose $\geq 7.0 \mathrm{mmol} / \mathrm{L}$. Sensitivity indicators of liver function: normal value of alanine aminotransferase (ALT): 0-40 U/L, normal value of aspartate aminotransferase (AST): 0-40 U/L, total bilirubin (TB): 1.71-17.1 $\mu \mathrm{mol} / \mathrm{L}$.

\subsection{Statistical methodology}

The SPSS23.0 statistical software was used to process the data., and the measurement data were expressed as mean \pm standard deviation ( $\pm s$ ) and analyzed by a t-test. Enumeration data were expressed as a rate (\%) and analyzed by the $\chi^{2}$ test. Multivariate logistic regression was performed to analyse the influencing factors. The difference was statistically significant when $P<0.05$.

\section{Results}

\subsection{Distribution of dyslipidemia}

Of the 43092 elder people included in this analysis, 12338 were detected with dyslipidemia, and the prevalence of dyslipidemia was $28.6 \%$. Low HDL-C accounted for the majority of dyslipidemia diseases, accounting for $48.28 \%$. The lowest detection rate was high TG combined with low HDL-C (1.81\%). Among patients with dyslipidemia, 54.53\% were females, and $45.47 \%$ were males. The detection rate of low HDL-C in male patients was significantly higher than that in female patients, and the difference was statistically significant $(P<0.05)$. There was no statistically significant difference in the proportion of high TG combined with low HDL-C and high TC combined with high TG and low HDL-C between genders $(P>0.05)$. (As shown in Table 1$)$ 
Table 1

Distribution status of dyslipidemia in males and females (n (\%)).

\begin{tabular}{|c|c|c|c|c|c|c|c|c|}
\hline Gender & $n$ & $\begin{array}{l}\text { Low } \\
\text { HDL-C }\end{array}$ & $\begin{array}{l}\text { High } \\
\text { TC }\end{array}$ & High TG & $\begin{array}{l}\text { High TG } \\
\text { combined } \\
\text { with low } \\
\text { HDL-C }\end{array}$ & $\begin{array}{l}\text { High TC } \\
\text { combined } \\
\text { with low } \\
\text { HDL-C }\end{array}$ & $\begin{array}{l}\text { High TC } \\
\text { combined } \\
\text { with high } \\
\text { TG }\end{array}$ & $\begin{array}{l}\text { High TC combined } \\
\text { with high TG and } \\
\text { low HDL-C }\end{array}$ \\
\hline Male & $\begin{array}{l}6728 \\
(54.53 \% \rrbracket\end{array}$ & $\begin{array}{l}3603 \\
(29.2 \%)\end{array}$ & $\begin{array}{l}368 \\
(2.98 \%)\end{array}$ & $\begin{array}{l}1713 \\
(13.88 \%)\end{array}$ & 412 (3.34\%) & 99 (0.80\%) & 393 (3.19\%) & $140(1.13 \%)$ \\
\hline Female & $\begin{array}{l}5610 \\
(45.47 \% \rrbracket\end{array}$ & $\begin{array}{l}2354 \\
(19.08 \%)\end{array}$ & $\begin{array}{l}511 \\
(4.14 \%)\end{array}$ & $\begin{array}{l}1747 \\
(14.16 \%)\end{array}$ & 326 (2.64\%) & $124(1.01 \%)$ & $423(3.43 \%)$ & 125 (1.01\%) \\
\hline$x^{2}$ & & 263.03 & 23.97 & 0.278 & 10.13 & 2.394 & 1.106 & 0.849 \\
\hline$P$ & & $<0.001$ & $<0.001$ & 0.598 & 0.001 & 0.122 & 0.293 & 0.357 \\
\hline
\end{tabular}

\subsection{Correlation analysis of dyslipidemia}

\subsubsection{Univariate analysis}

Univariate analysis showed that age, gender, smoking, drinking, blood sugar, blood pressure, weight, ECG, and TB were the influencing factors of dyslipidemia in the elderly, and the differences were statistically significant $(P<0.005)$. (Table 2) 
Table 2

Univariate analysis of dyslipidemia in elderly patients (n).

\begin{tabular}{|c|c|c|c|c|c|c|c|c|}
\hline \multirow[t]{2}{*}{ Groups } & \multirow[t]{2}{*}{$\mathrm{n}$} & \multicolumn{3}{|l|}{ Age } & \multicolumn{2}{|l|}{ Sex } & \multicolumn{2}{|c|}{ Blood Pressure } \\
\hline & & $60-70$ & $70-80$ & $>80$ & Male & Female & Normal & Abnormal \\
\hline $\begin{array}{l}\text { Normal } \\
\text { lipids }\end{array}$ & 30754 & 13484 & 14251 & 3019 & 17825 & 12929 & 22508 & 8246 \\
\hline Dyslipidemia & 12338 & 5556 & 5745 & 1037 & 6728 & 5610 & 9142 & 3196 \\
\hline$x^{2}$ & & 21.55 & & & 42.24 & & 3.73 & \\
\hline$P$ & & $<0.001$ & & & $<0.001$ & & 0.05 & \\
\hline \multirow[t]{2}{*}{ Groups } & \multirow[t]{2}{*}{$\mathrm{n}$} & \multicolumn{3}{|c|}{ Drinking status } & \multicolumn{2}{|c|}{ Blood glucose } & \multicolumn{2}{|l|}{ ECG } \\
\hline & & Never & Occasionally & Every day/often & Normal & Abnormal & Normal & Abnormal \\
\hline $\begin{array}{l}\text { Normal } \\
\text { lipids }\end{array}$ & 30754 & 24532 & 5319 & 861 & 25865 & 4889 & 16514 & 14240 \\
\hline Dyslipidemia & 12338 & 10012 & 2027 & 270 & 10145 & 2193 & 7088 & 5250 \\
\hline$x^{2}$ & & 18.50 & & & 22.59 & & 50.02 & \\
\hline$P$ & & $<0.001$ & & & $<0.001$ & & $<0.001$ & \\
\hline \multirow[t]{2}{*}{ Groups } & \multirow[t]{2}{*}{$\mathrm{n}$} & \multicolumn{3}{|l|}{ Body weight } & \multicolumn{2}{|l|}{ ALT } & \multicolumn{2}{|l|}{ AST } \\
\hline & & Underweight & Normal & Overweight/Obesity & Normal & Abnormal & Normal & Abnormal \\
\hline $\begin{array}{l}\text { Normal } \\
\text { lipids }\end{array}$ & 30754 & 1805 & 17701 & 11248 & 26071 & 4683 & 27110 & 3644 \\
\hline Dyslipidemia & 12338 & 531 & 6412 & 5395 & 10374 & 1964 & 10948 & 1390 \\
\hline$x^{2}$ & & 205.56 & & & 3.22 & & 2.90 & \\
\hline$P$ & & $<0.001$ & & & 0.07 & & 0.089 & \\
\hline \multirow[t]{2}{*}{ Groups } & \multirow[t]{2}{*}{$\mathrm{n}$} & \multicolumn{3}{|c|}{ Smoking status } & \multicolumn{4}{|l|}{ TB } \\
\hline & & Never & Smoke & Quit & Normal & $\begin{array}{l}\text { Slightly } \\
\text { low }\end{array}$ & $\begin{array}{l}\text { Slightly } \\
\text { high }\end{array}$ & \\
\hline $\begin{array}{l}\text { Normal } \\
\text { lipids }\end{array}$ & 30754 & 19870 & 7333 & 3497 & 25539 & 850 & 4365 & \\
\hline Dyslipidemia & 12338 & 8203 & 2736 & 1366 & 10116 & 570 & 1652 & \\
\hline$x^{2}$ & & 16.06 & & & 97.30 & & & \\
\hline$P$ & & $<0.001$ & & & $<0.001$ & & & \\
\hline
\end{tabular}

\subsubsection{Multivariate Logistic regression analysis}

Whether the lipid profile was abnormal or not was taken as the dependent variable $(0=$ normal, $1=$ abnormal $)$ and the factors influencing blood lipids in univariate analysis $(P<0.05)$ were used as independent variables for multivariate Logistic regression analysis.OR $>1, P<0.05$ ). (Table 3 ) The results of the analysis confirmed that female gender, overweight/obesity, abnormal blood glucose, and high ALT may all be the risk factors for dyslipidemia in the elderly population. 
Table 3

Multivariate Logistic regression analysis of dyslipidemia in the elderly in Wuwei.

\begin{tabular}{|c|c|c|c|c|c|c|c|}
\hline Variate & Control group & $\beta$ & Standard error & Wald $X^{2}$ & $P$ & OR & $95 \% \mathrm{Cl}$ \\
\hline \multicolumn{8}{|l|}{ Age (years) } \\
\hline $70-80$ & \multirow[t]{2}{*}{$60-70$} & 0.007 & 0.023 & 0.088 & 0.767 & 1.007 & $0.963-1.052$ \\
\hline$>80$ & & -0.12 & 0.04 & 8.982 & 0.003 & 0.0887 & $0.82-0.959$ \\
\hline \multicolumn{8}{|l|}{ Sex } \\
\hline Female & Male & 0.133 & 0.028 & 22.467 & $<0.001$ & 1.142 & $1.081-1.206$ \\
\hline \multicolumn{8}{|l|}{ Smoking status } \\
\hline Smoke & \multirow[t]{2}{*}{ Never } & 0.041 & 0.034 & 1.492 & 0.222 & 1.042 & $0.975-1.114$ \\
\hline Quit & & 0.052 & 0.042 & 1.501 & 0.220 & 1.053 & $0.969-1.144$ \\
\hline \multicolumn{8}{|l|}{ Drinking status } \\
\hline Occasionally & \multirow[t]{2}{*}{ Never } & -0.029 & 0.035 & 0.721 & 0.396 & 0.971 & $0.908-1.039$ \\
\hline Often/Every day & & -0.216 & 0.073 & 8.724 & 0.003 & 0.806 & $0.698-0.930$ \\
\hline \multicolumn{8}{|l|}{ Body weight } \\
\hline Underweight & \multirow[t]{3}{*}{ Normal } & -0.208 & 0.052 & 16.18 & $<0.001$ & 0.812 & $0.734-0.899$ \\
\hline Overweight/ & & 0.269 & 0.022 & 144.26 & $<0.001$ & 1.309 & $1.253-1.368$ \\
\hline \multicolumn{7}{|l|}{ Obesity } & \\
\hline \multicolumn{8}{|l|}{ Blood glucose } \\
\hline Abnormal & Normal & 0.108 & 0.029 & 14.44 & $<0.001$ & 1.114 & $1.054-1.179$ \\
\hline \multicolumn{8}{|l|}{ ECG } \\
\hline Abnormal & Normal & -0.141 & 0.022 & 41.88 & $<0.001$ & 0.869 & $0.833-0.907$ \\
\hline \multicolumn{8}{|l|}{ TB } \\
\hline Abnormal & Normal & -0.051 & 0.026 & 3.95 & 0.047 & 0.95 & 0.904-0.999 \\
\hline \multicolumn{8}{|l|}{ ALT } \\
\hline Abnormal & Normal & 0.078 & 0.034 & 5.411 & 0.02 & 1.081 & $1.021-1.155$ \\
\hline
\end{tabular}

\section{Discussion}

This study found that the prevalence of dyslipidemia was $28.6 \%$ in the elderly in Wuwei, of which the incidence was $15.61 \%$ in males and $13.02 \%$ in females. It showed that the incidence of dyslipidemia in males was significantly higher than that in females, and the difference was statistically significant. Next, according to the proportion of related dyslipidemia types obtained from the included data, the highest incidence of dyslipidemia is low HDL-C, and the lowest incidence is high TG combined with low HDL-C. It is the same as the result that the highest incidence of dyslipidemia diseases is low HDL-C among the general population by some researches ${ }^{[6]}$. However, it is inconsistent with the constituent ratio of dyslipidemia in the elderly in Zhongshan City in the study ${ }^{[7]}$. The cause of this difference may be related to regional factors or dietary habits, and the specific reason needs to be further studied.

Multivariate logistic regression analysis demonstrated that age, gender, overweight/obesity, hyperglycemia, and high AST are independent risk factors for dyslipidemia in elderly patients. Also, the epidemiological research report of dyslipidemia pointed out that there are differences in the incidence of different ages and different genders, and this is consistent with the conclusions 
drawn from our study. The results of the analysis also found that elderly women had a 1.14-fold higher risk of dyslipidemia than men. The loss of estrogen's protective effect on lipid metabolism or associated changes in endocrine metabolism after

menopause in elder women may be responsible for this result ${ }^{[8,9]}$. Therefore, the prevention and treatment of dyslipidemia in elder women should be strengthened in clinical practice.

The results of this study indicated that the risk of dyslipidemia is higher at the age of 70-80 years than that at the age of $60-70$ years, and the risk of disease is reduced after the age of 80 . But in previous existing studies, the reported age levels of the high incidence of dyslipidemia vary, and the mechanism of changes in blood lipid levels with age has not been clarified ${ }^{[10]}$.

Overweight/obesity is also a risk factor for dyslipidemia, while underweight patients have a low risk of dyslipidemia, and it indicates that dyslipidemia is associated with obesity. Insulin resistance in obese subjects reduces LDL-C level and reduces lipoprotein lipase activity, both of which cause slow clearance of very-low-density lipoprotein, TC, LDL-C, etc., thereby triggering abnormal lipid changes ${ }^{[11]}$.

Previous studies have found that elder people with abnormal liver function have an increased risk of dyslipidemia, and the two are mutually causal ${ }^{[12]}$. Our study demonstrated that ALT, a diagnostic indicator of liver function, is a risk factor for dyslipidemia, which is the same as the conclusion of the previous conclusion. The liver is the main organ for the breakdown and synthesis of blood lipids; After it injury, the rate of blood lipid degradation is slowed down and the lipid part in the blood cannot be cleaned in time. Excessive deposition occurs in the hepatocytes. Inflammatory necrosis and cellular fibrosis are induced after the activation of related cells ${ }^{[13]}$. Therefore, attention should be paid to the treatment of liver dysfunction in the elderly group with liver dysfunction to reduce the occurrence of dyslipidemia.

Previous studies have indicated that smoking and alcohol consumption are independent risk factors for dyslipidemia [14-16]. However, this study did not find an effect of smoking and alcohol consumption on dyslipidemia. The possible reason for the different conclusions may be that this physical examination data recorded the frequency of alcohol consumption and smoking but did not clearly record the amount of smoking and alcohol consumed.

\section{Conclusions}

In summary, the incidence of dyslipidemia was relatively low among the elderly population in Wuwei, and female gender, overweight/obesity, abnormal blood glucose, and high ALT are risk factors for dyslipidemia. Therefore, it is recommended that the elderly population in this area improve life habits, control body weight, improve liver function. In particular, strengthen the prevention and treatment of dyslipidemia in the elder women, so as to reduce the risk of dyslipidemia and reduce the occurrence of cardiovascular disease.

\section{Abbreviations}

TG - triacylglycerol

TC - total cholesterol

LDL-C low-density lipoprotein cholesterol

HDL-C - high-density lipoprotein cholesterol

ECG - electrocardiograph

BMI - body mass index

SBP - systolic blood pressure

DBP - diastolic blood pressure 
ALT - alanine aminotransferase

AST - aspartate aminotransferase

TB - total bilirubin

\section{Declarations}

\section{Ethics approval and consent to participate:}

According to Article 39 of the Measures for the Ethical Review of Biomedical Research Involving Human Subjects (2016) issued by the National Health Commission of the People's Republic of China, this study is exempt from ethical review.

\section{Consent for publication:}

Not applicable.

\section{Availability of data and materials】}

All data generated or analyzed during this study are included in this published article and its supplementary information files.

\section{Competing interests}

The authors declare that they have no competing interests.

\section{Funding:}

No funding.

\section{Authors' contributions:}

These authors contributed equally to this work: LXC, YJS, and author JZH helped perform the analysis with constructive discussions.

\section{Acknowledgements】}

Not applicable

\section{References}

1. Sando KR, Michelle K. Nonstatin therapies for management of dyslipidemia: a review [J].Clin Ther.2015; 37(10):2153-79.

2. Li SN, Zhang LF, Wang X, Chen Z, Dong Y, Zheng CY, et al. Status of Dyslipidemia Among Adults Aged 35 Years and Above in China. Chinese Circulation Journal.2019,07:681-687.

3. Zhu JR, Gao RL, Zhao SP, Lu GH, Zhao D, Li JJ. 2016 Chinese guideline for the management of dyslipidemia in adults [J].Chinese Circulation Journal.2016; 16(10):15-35. doi:10.3760/cma.j.issn.1671-7368.2017.01.006.

4. Moran A,GU D, Dong Z, et al. Future cardiovascular disease in China: Markov model and risk factor scenario projections from the Coronary Heart Disease Policy Model-China [J].Circulation Cardiovascular Quslity \&Outcomes.2010;3(3):243. 
5. Writing Group of Chinese Guidelines for the Management of Hypertension, Chinese Hypertension League, Chinese Society of Cardiology Chinese Hypertension Committee of the Chinese Medical Doctors Association, The Hypertension Branch of China Healthcare International Exchange Association, The Hypertension Branch of the Chinese Geriatrics Society. 2018 Chinese guidelines for the management of hypertension. Chinese Journal of Cardiovascular Medicine. 2019;24(1):24-56.

6. Yi Q, Sun L, Zhao HL. Analysis on blood lipids of 8340 elderly people over the age of 60 in Huacao Community, Shanghai. Journal of Public Health and Preventive Medicine.2016; 27(5):52-55.

7. Zheng LY. Analysis on the detection and risk factors of dyslipidemia in the elderly in Sanxiang Town, Zhongshan city. Chinese Journal of Modern Drug Application. 2019;(09):230-1.

8. Tian Y, Zheng TP. Effect of postmenopausal estrogen supplementation on blood lipid metabolism in women[J]. Journal of Practical Obstetrics and Gynecology. 2018,11:826-829.

9. GEP,DONG C,REN X,et al. The high prevalence of low HDLcholesterol levels and dyslipidemia in rural populations in northwestern China[J]. PLoS One.2015;10(12):e0144104.

10. 2019; (05):460-4. SHI MM, Zhang X, Li N, Hu JF. Establishment of nomogram for dyslipidemia related factors. Journal of Preventive Medicine. 2019; (05):460-4.

11. Xie MT, Yu J, Zou DS, Zhou SX, Yu P, Xun JQ, et al. Analysis of the interaction between overweight or obesity and hyperglycemia on dyslipidemia [J]. Shangdong Medical Journal.2016;56( 46) : 39-41.

12. Ja N, Song XL, Zhang LN, Tan H, Du YL. Prevalence and risk factors of dyslipidemia among the elderly in Yubei,Chongqing [J]. Chinese Journal of Gerontology. 2019;(21):5201-5.

13. Lee J,Son $\mathrm{H}$,Ryu $\mathrm{OH}$. Management status of cardiovascular disease risk factors for dyslipidemia among korean adults[J].Yonsei Med J.2017;58(2):326.

14. Zhao Y, Ma AJ, Fang K, Li H, Xie J, Zhou Y, et al. A correlation study on the prevalence of dyslipidemia and risk factors among residents aged 18-65 years in Beijing in 2014 [J].Chinese Journal for Clinicians.2017;45(11):25-28.

15. Liu JF, Chen Z, Yang FK, Chen, Hu JQ, Li D. Prevalence and influencing factors of dyslipidemia among the elderly in Changsha: a community-based study [J].Journal of Central South University(Medical Science).2014;39(8):797801.

16. LUO J,MA Y,YU Z,et al. Prevalence,awareness,treatment and control of dyslipidemia among adults in northwestern China冈the cardiovascular risk survey [J]. Lipids Health Dis.2014;(13):4. 